\title{
THE FORM OF THE HAIR FOLLICLE IN THE HUMAN SCALP AS AN INDICATOR OF HUMAN RELATIONSHIPS
}

\author{
by Brian Plomley and Les Barber
}

(with two tables and nine plates)

PLOMLEY, B. \& BARBER, L., 1991 (20:xii): The form of the hair follicle in the human scalp as an indicator of human relationships. Pap. Proc. R. Soc. Tasm. 125: 45-54. https://doi.org/10.26749/rstpp.125.45 ISSN 0080-4703. Queen Victoria Museum and Art Gallery, Launceston, Tasmania, Australia 7250 (BP); and Department of Medical Sciences, University of Tasmania, Newnham Drive, Newnham, Tasmania, Australia 7248 (LB).

\begin{abstract}
The form of the hair follicle has been examined in some human isolates. There is no relationship between follicular structure and hair form, that is, similar hair forms may be the end product of different follicular structures. Such diversity means that it is not possible to use hair form as an indicator of human relationships. The usefulness of follicular structure as such an indicator must await a much wider sampling from an extensive variery of human isolates.
\end{abstract}

Key Words: hair follicle, Andaman, Australian aboriginal, Bantu, Bushman, Chinese, New Guinea, Tasmanian aboriginal, Zulu, Australia.

\section{INTRODUCTION}

A concern with human relationships has long been of importance to humans. Probably this had its origins in feelings of superiority of one group over another, feelings which then became associated with religion. It was not until the 18th century in Europe that the study of human relationships became of interest to savants and took on a scientific manner of thinking. Different peoples were considered to have developed as isolates of a single creation by God, and it was thought that scientific studies might reveal the interrelations of the various groups. Several basic forms were postulated, the so-called races of Homo sapiens, and their distribution was related to the pathways of migration of humans over the Earth.

The form of the hair of the scalp and the colour of the skin were the first characteristics of the human body to be considered as indicators of human relationships. The colour of the skin was early found difficult to systematise and was used only to differentiate socially between so-called superior beings having white skins and inferior ones with black skins. It is not to be wondered at that skin colour defied classification when the production of melanin pigments is genetically so complex.

An association between the form of the scalp hair and human groups was noticed by the ancient Greeks, the historian Herodotus drawing attention to it in respect of the soldiers composing the army of Xerxes (The Histories, book VII). The first attempts to formulate such differences in systems of classification were made by French scientists of the late 18th century. These systems have been revised from time to time since then, in attempts to make them fit better the complexity of human relationships, but none has been found which provides a sound basis for the classification of humans (Trotter 1938).

The attempts to use hair form and skin colour were early supplemented by the use of the form of the human skull as an indicator of human relationships. Johan Friedrich Blumenbach (1752-1840), Professor in the Faculty of Medicine at Göttingen, was the pioneer of such studies, and his research led to the formation, in the 19 th century, of vast collections of human crania, which are scattered through many museums over the world. These 19th-century collections are especially valuable because their material had come from peoples at a time when many of them had mingled only to a limited extent with foreigners, so that these collections provide samples of the original populations.

The high hopes entertained of obtaining meaningful data on human relationships from cranial studies did not eventuate. Basically, this was because relationships between the two parts of the skull, that is, the braincase and the facial skeleton, are complex. As a result, much of the early research was too crude to have much meaning. However, developments in statistical theory have enabled students to deal with cranial measurements in such a way that they have some relevance.

With the discovery of the genetic mechanism of inheritance and the elaboration of methods for the study of the human blood groups, another approach to the study of human relationships was opened up. Such studies have provided information about relationships between neighbouring peoples. In the future, it may be expected that new techniques will allow comparisons to be made between groups by the use of body fluids and tissues, mummified organs and bone, and in these, early collections of human remains will play an important part.

\section{FORM OF THE SCALP HAIR}

Systems of classification of the form of the scalp hair have been based upon on the nature of the hair, that is, whether it hangs straight, is waved or curls in ringlets. An explanation of these various types has been sought, largely in terms of the cross-section of the hair and/or the structure of the follicle which produces and carries the hair from the germinal bulb to the surface of the scalp. It is clear, however, that, over the whole time it is growing, the type of hair will not only be influenced by what occurs in the bulb, but is likely, also, to be affected by the follicle - its form, its length and the activity of the sebaceous glands - as well as by the changes in the chemical nature of the keratins which compose the hair during the time it is moving from the bulb to the surface of the scalp. In addition, there will be many indirect influences, 
such asthe state of the endocrine system, the health and nutrit ich of the individual, and so on.

Most reearch has dealt with the form of the hair rather than with $\mathrm{h}$ h follicle producing it. Peter Browne was the first, in 1853, ti give detailed consideration to the cross-sectional form of he hair (Trotter 1938); he was followed by PrunerBey (1 84, 1865), with particulars for a wide range of human types. Their work has been followed by a number of other studies (Trotter 1938). Few students thought that the form of the follicle was the principal agent in the development of hair form, finding in general that a straight hair shaft was associa $t \in d$ with a round cross-section and a curved shaft with an oval closs-section. In most of these studies, however, only two or avery few different peoples were compared.

The objet of the present paper was to study the form of the hait follide in several different peoples so as to explore human relation sips generally in this way. Although the number of differe n tgroups studied was small (perhaps also because the sam ples vere too small), the work has produced information which points to ways of differentiating peoples but not to their relaionships.

\section{THE MATERIAL}

Samples of scalp were obtained from the following peoples and in diriduals - Andaman (3 individuals), Australian aborigi nal (5), Bantu (8), Bushman (9), Chinese (Singapore) (12), New Guinea (11), Tasmanian aboriginal (1), Zulu (24).

Nearly all this material was obtained from autopsies or from medical cadavers and has been preserved in formol saline or in rectified spirit $(95 \%$ alcohol); a few specimens had been dried.

\section{METHODS OF PREPARATION}

Preliminary research, carried out between 1963 and 1967 at the University of New South Wales and at University College, London, was based largely upon serial sections of the scalp, using standard techniques of preparation and staining, and a few whole mounts of slices of scalp were examined to determine the distribution of the follicles. Study of the Tasmanian hair follicle was carried out at this time (Plomley \& Baldwin 1964), and the particulars which form part of this paper were recorded then.

In the present study the arrangement of the hair follicles in the scalp was studied in two vertical sections, each about $5 \times 2 \mathrm{~mm}$, and full skin thickness, taken at right angles to one another, and a third piece of scalp about $15 \times 10 \mathrm{~mm}$, to show the surface of the scalp in relation to the hair. These pieces were then treated as follows: to $70 \%$ alcohol for 24 hours; to $95 \%$ alcohol for 6-8 hours; to a mixture of equal parts of 95\% alcohol and LKB 2218-500 HISTORESIN infiltration solution overnight at room temperature; to full strength HISTORESIN solution for 6 hours. They were then embedded in LKB HISTORESIN embedding medium in a mould; polymerisation occurred within 2 hours and the expelled fluid was drained off the block, which could be removed from the mould after 24 hours. After embedding, the specimens were photographed on Kodak Gold 200 film, using an Olympus stereoscopic microscope.

\section{FORM OF THE FOLLICLE IN SEVERAL ISOLATES}

The data on the follicle will be presented first in terms of its size, form, direction and densiry, and the relationships of bulb and shaft. The principal points of interest in the data are summarised in table 1 .

\section{Andaman (PI.1 A,B)}

Size

Thick and fairly uniform.

Form

Markedly curved, the curvatures all in the same sense.

\section{Direction}

The follicles approach the surface obliquely at end of their curve; having pierced the surface of the scalp, the hair continues the direction of the follicle.

Density

The follicles arising from the groups of bulbs keep together in the epidermis, so that there are wide spaces between the groups, and they meet on the surface in a pigmented spot.

Bulb

The germinal bulbs are set at an angle to the shaft of the follicle; the bulbs form groups of two or three, usually three.

\section{Australian Aboriginal (PI.2 A,B)}

Size

Differences in diameter not great, the range not approaching the extremes of fine and very thick.

Form

Follicles usually slightly and uniformly curved, but sometimes straight, or nearly so; curves all in the same sense, follicles seldom crossing one another; the follicles arise at different depths.

Direction

Follicles approach surface obliquely, or nearly so; having pierced the surface of the scalp, the hair continues the direction of the follicle.

\section{Density}

Intermediate; the germinal bulbs have no specific arrangement, being distributed haphazardly in the epidermis; it is usual for two hairs to emerge from the scalp close to one another (but not as a doublet) on a small pigmented area.

Bulb

The bulbs are clubbed terminally, this part continuing into the shaft of the follicle without a bend. 
TABLE 1

Summary of follicular characters for the human isolates examined here

\begin{tabular}{|c|c|c|c|c|c|c|c|c|c|}
\hline & \multirow[t]{2}{*}{ Andaman } & \multirow{2}{*}{$\begin{array}{l}\text { Australian } \\
\text { aboriginal }\end{array}$} & \multirow[t]{2}{*}{ Bantu } & \multirow[t]{2}{*}{ Bushman } & \multirow{2}{*}{$\begin{array}{l}\text { Chinese } \\
\text { (Singapore) }\end{array}$} & \multicolumn{2}{|c|}{ New Guinea } & \multirow[t]{2}{*}{ Tasmanian } & \multirow[t]{2}{*}{ Zulu } \\
\hline & & & & & & Highla & Moresby & & \\
\hline \multicolumn{10}{|l|}{ Size } \\
\hline large & $\mathrm{x}$ & & $\mathrm{x}$ & & $\mathrm{x}$ & $\mathrm{x}$ & $\mathrm{x}$ & $\mathrm{x}$ & \\
\hline medium & & $\mathrm{x}$ & & $\mathrm{x}$ & & & & & $\mathrm{x}$ \\
\hline small & & & & $\mathrm{x}$ & $\mathrm{x}$ & & & & \\
\hline mixed & & $\mathrm{x}$ & $\mathrm{x}$ & & $\mathrm{x}$ & $\mathrm{x}$ & $\mathrm{x}$ & & $\mathrm{x}$ \\
\hline \multicolumn{10}{|l|}{ Form } \\
\hline straight & & & & & $\mathrm{x}$ & & $\mathrm{x}$ & & \\
\hline slight curve & & $\mathrm{x}$ & & & & & $\mathrm{x}$ & & \\
\hline strong curve & $\mathrm{x}$ & & $\mathrm{x}$ & $\mathrm{x}$ & & $\mathrm{x}$ & & $\mathrm{x}$ & $\mathrm{x}$ \\
\hline \multicolumn{10}{|l|}{ Direction } \\
\hline direct & & & $\mathrm{x}$ & & $\mathrm{x}$ & & $\mathrm{x}$ & & $\mathrm{x}$ \\
\hline oblique & $\mathrm{x}$ & $\mathrm{x}$ & & $\mathrm{x}$ & $\mathrm{x}$ & $\mathrm{x}$ & & $\mathrm{x}$ & \\
\hline \multicolumn{10}{|l|}{ Density overall } \\
\hline heavy & & & $\mathrm{x}$ & & $\mathrm{x}$ & $\mathrm{x}$ & $\mathrm{x}$ & & \\
\hline medium & $\mathrm{x}$ & $\mathrm{x}$ & & $\mathrm{x}$ & $\mathrm{x}$ & & & & $\mathrm{x}$ \\
\hline \multicolumn{10}{|l|}{ Density arrangement } \\
\hline deep-haphazard & & $\mathrm{x}$ & $\mathrm{x}$ & & $\mathrm{x}$ & $\mathrm{x}$ & $\mathrm{x}$ & & $\mathrm{x}$ \\
\hline deep-doublet, triplet & $\mathrm{x}$ & & & $\mathrm{x}$ & $\mathrm{x}$ & & & & \\
\hline surface-haphazard & & & & & $\mathrm{x}$ & $\mathrm{x}$ & & & \\
\hline surface-doublet,triplet & $\mathrm{x}$ & $\mathrm{x}$ & $\mathrm{x}$ & $\mathrm{x}$ & $\mathrm{x}$ & & $\mathrm{x}$ & & $\mathrm{x}$ \\
\hline \multicolumn{10}{|l|}{ Bulb type } \\
\hline shaft straight & & $\mathrm{x}$ & & & $\mathrm{x}$ & & & $\mathrm{x}$ & \\
\hline shaft clubbed & $\mathrm{x}$ & & $\mathrm{x}$ & $\mathrm{x}$ & & $\mathrm{x}$ & $\mathrm{x}$ & & $\mathrm{x}$ \\
\hline \multicolumn{10}{|l|}{ Bulb depth } \\
\hline deep & $\mathrm{x}$ & $\mathrm{x}$ & $\mathrm{x}$ & $\mathrm{x}$ & $\mathrm{x}$ & $\mathrm{x}$ & $\mathrm{x}$ & & $\mathrm{x}$ \\
\hline mixed & & $\mathrm{x}$ & & & $\mathrm{x}$ & & & & \\
\hline
\end{tabular}

\section{Bantu (PI.3 A,B)}

Size

A mixture of diameters, mostly large.

\section{Form}

Most follicles strongly and smoothly curved; in some scalps (three) the follicles all curved in same direction, but in others (three) the amount of curving differed and follicles had no definite arrangement.

\section{Direction}

Although curved, the follicle approaches the surface of the scalp in such a way that the hair issues from the scalp at right angles to it or nearly so; having pierced the surface, the hair continues the curve of the follicle.

\section{Density}

Some variation in density, but high in all; no definite arrangement of follicles apparent in the scalp; doublets common at skin surface.

Bulb

Germinal bulbs set obliquely to shaft and heavily pigmented.

\section{Bushman (PI. 4 A,B)}

Size

Medium to small.

Form

Usually strongly curved, but some less so and almost straight.

Direction

Follicles approach surface more or less obliquely; having pierced the scalp, the hair continues the direction of the follicle.

Density

The groups of follicles keep together in the epidermis, so that there are wide spaces between the groups, which meet at the surface in a pigmented spot.

Bulb

Bulbs not set at angle to shaft of follicle; occur in groups of two (occasionally three?). 

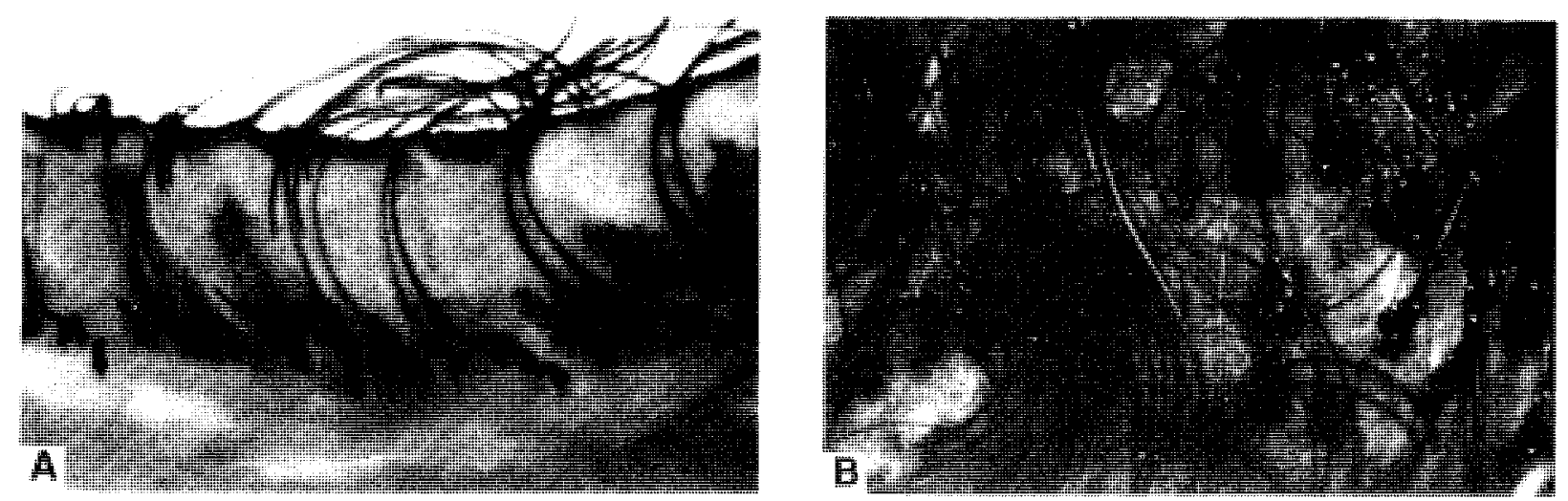

PLATE 1

Andaman: (A) scalp section; (B) scalp surface.
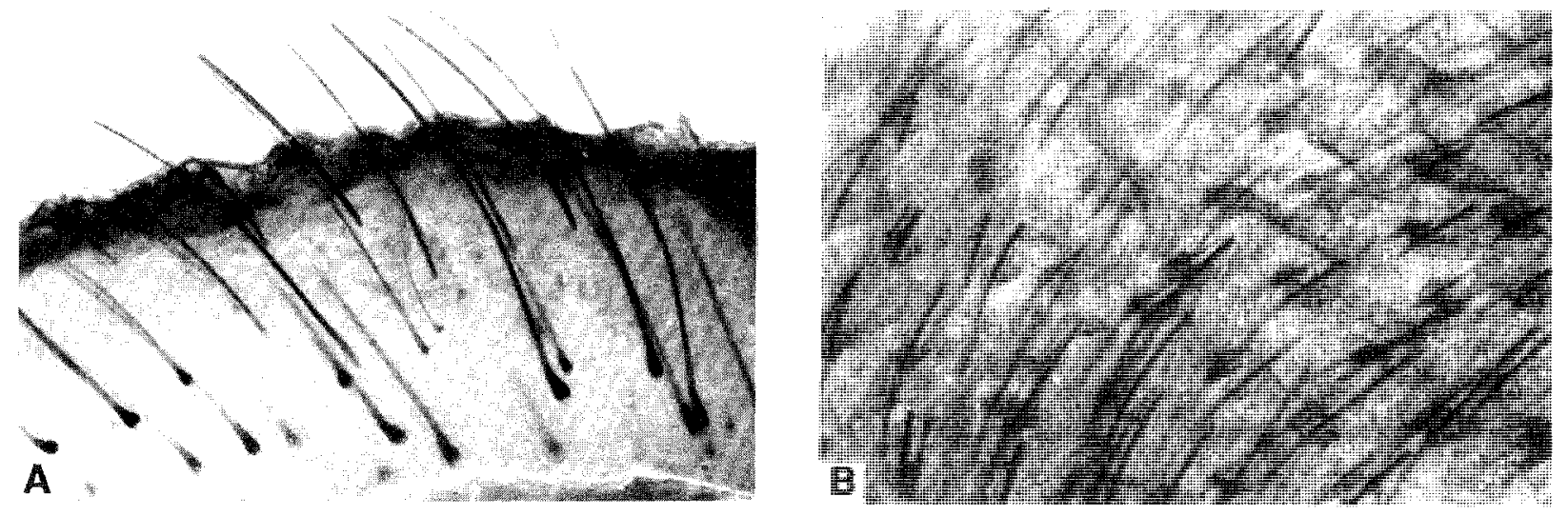

PLATE 2

Australian aboriginal: (A) scalp section; (B) scalp surface.
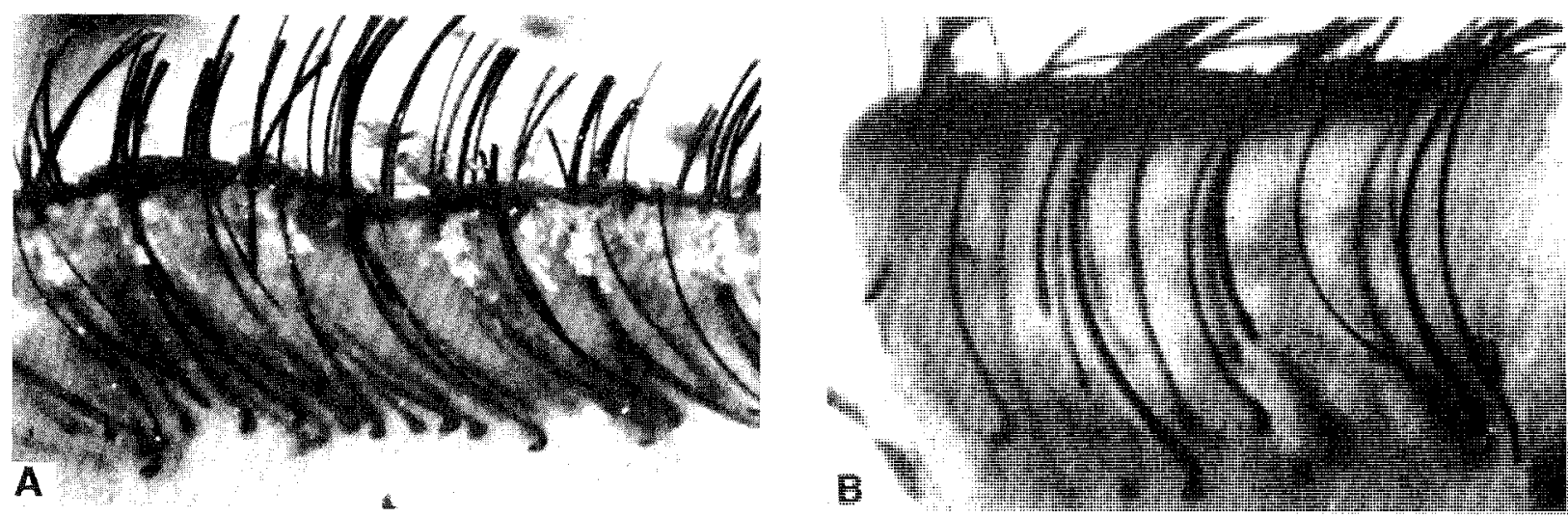

PIATE 3

Bantu: (A) scalp section; (B) scalp section. 

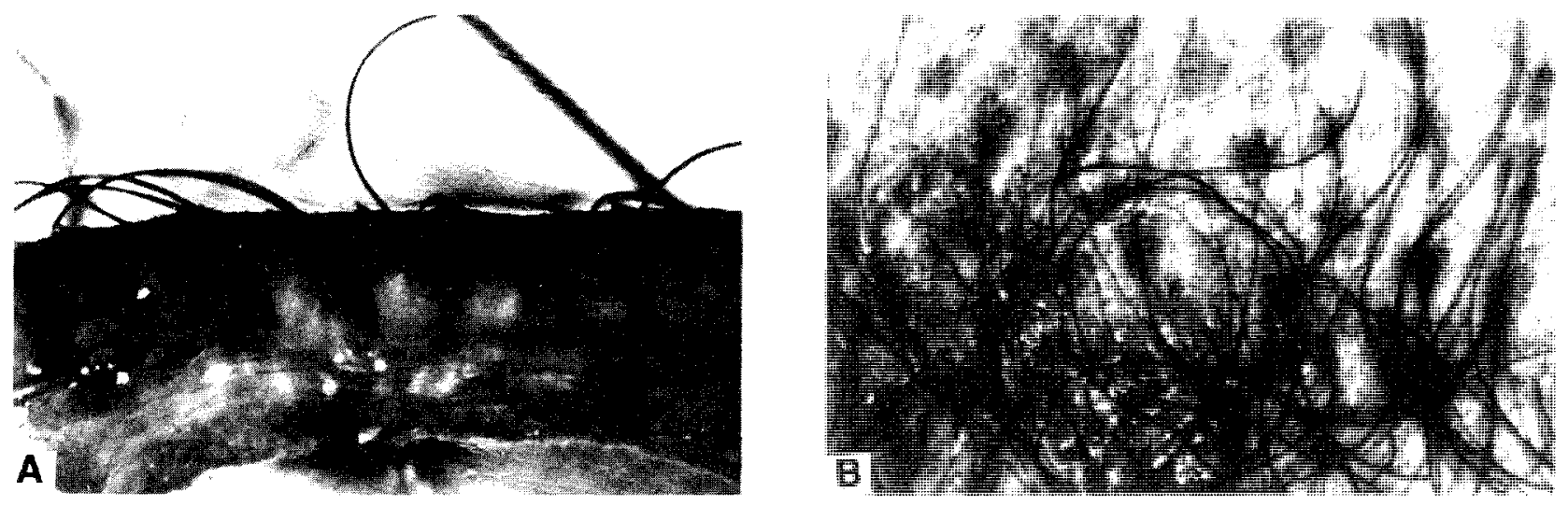

\section{PLATE 4}

Bushman: (A) scalp section; (B) scalp surface.

\section{Chinese (Singapore) (PI. 5 A-F)}

Size

Most of the scalps had a mixture of thick and fine hairs, but sometimes diameter uniform and thick.

\section{Form}

Straight or nearly so.

\section{Direction}

The follicles (and bulbs) may be directed either at right angles to the surface of the scalp, or approach it obliquely; in the latter case, the follicle may be slightly curved. (Is it the obliquely placed follicle which is sometimes found associated with the slight wave of some Chinese scalp hair?)

\section{Density}

There is a good deal of variation in follicular density, some scalps having a larger number of follicles per unit area than others, and these may arise over a wide range of depths. When the follicles are sparse their distribution is haphazard, but when dense there is perhaps a tendency to run obliquely to the surface, so that two follicles reaching it side by side appear to form a doublet, with, in one very dense specimen, a regular arrangement of follicles at the surface, clumps of two or three adjacent hairs being distributed in a regular system of squares although the origins of the follicles were haphazard.

\section{Bulb}

The bulbs may be set a little obliquely to the shaft, but essentially they continue straight into it.

\section{New Guinea}

Woolly hair (Highlands) (P1.6 A,B)

Size

A mixture of diameters, but mostly thick.

Form

Strongly and smoothly curved, all sizes the same.

\section{Direction}

Although strongly curved, the follicle approaches the surface in such a way that the hair issues from the scalp at right angles to it or nearly so; having pierced the surface, the hair continues the curve of the follicle.

Density

About the same in both scalps; there is no definite arrangement of follicles either at their origin or at the surface, where the distribution of hair is both haphazard and uniform.

Bulb

Bulb set obliquely to shaft.

Port Moresby series (Pl. 7 A,B)

Size

A mixture of sizes with large diameters predominant; the latter little different from those of the woolly haired subject.

\section{Form}

Follicles either slightly curved or straight (none strongly curved); the hairs protruding from the surface appear to be a mixture of straight and slightly curved forms.

\section{Direction}

The follicles meet the scalp at right angles to it or slightly obliquely.

\section{Density}

High in all subjects; no definite arrangement at origins; arrangement at surface not clear, but in one subject the hairs issue in doublets which are distributed irregularly.

Bulb

Bulb set obliquely to shaft. 

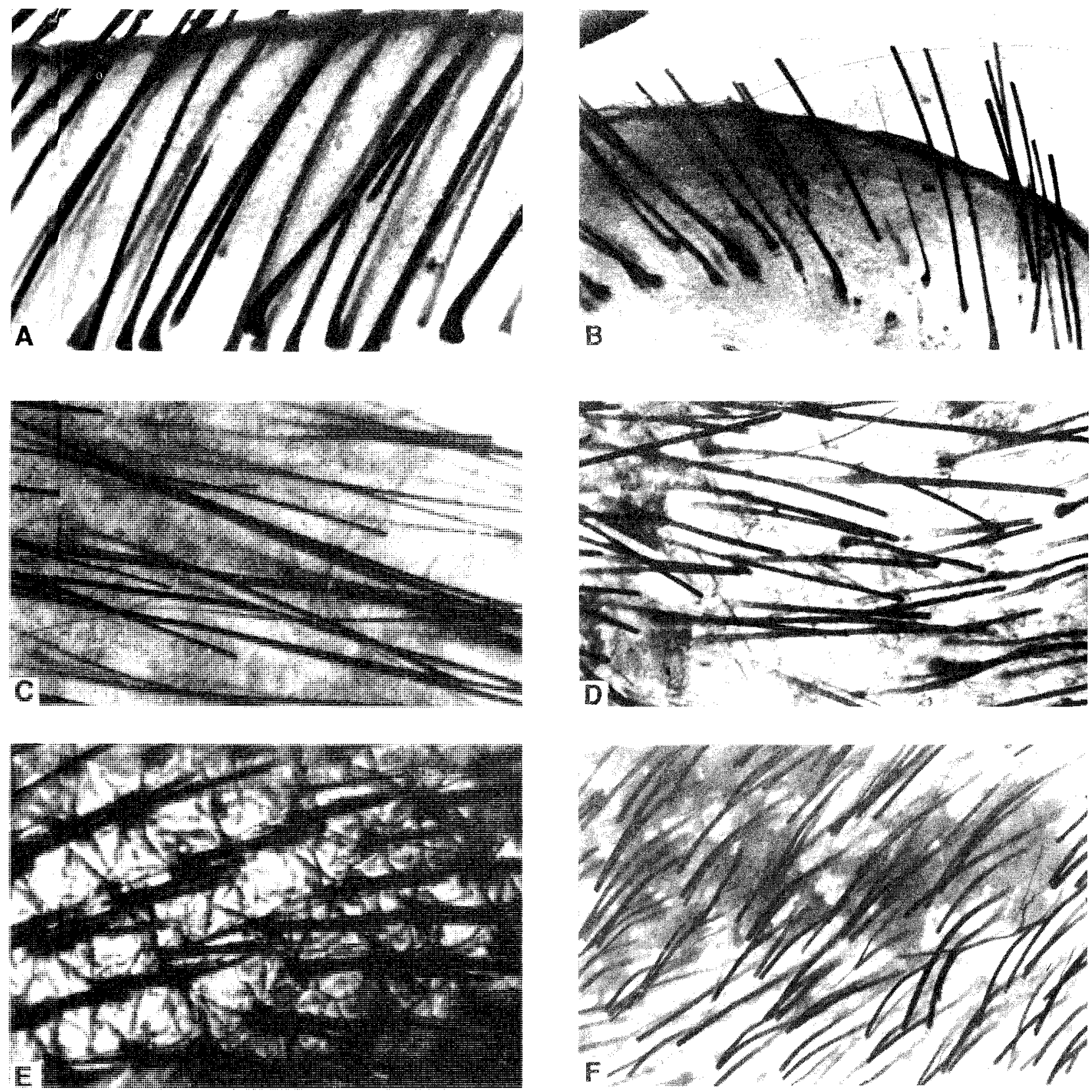

PLATE 5

Chinese: (A) scalp section; (B) scalp section; (C) scalp surface; (D) scalp surface; (E) scalp surface; (F) scalp surface.

Size

Tasmanian (PI. 8)

Large diameter.

Form

Follicle strongly curved; lies obliquely in scalp.

Direction

Follicle meets surface obliquely, the hair continuing the curvature of the follicle.
Density

Medium.

Bulb

Appears to continue into shaft.

Note

There seems to be a tendency for the follicles at the surface to lie in pairs, with wide spacing between them; deeply, the follicles seem to be distributed haphazardly. 

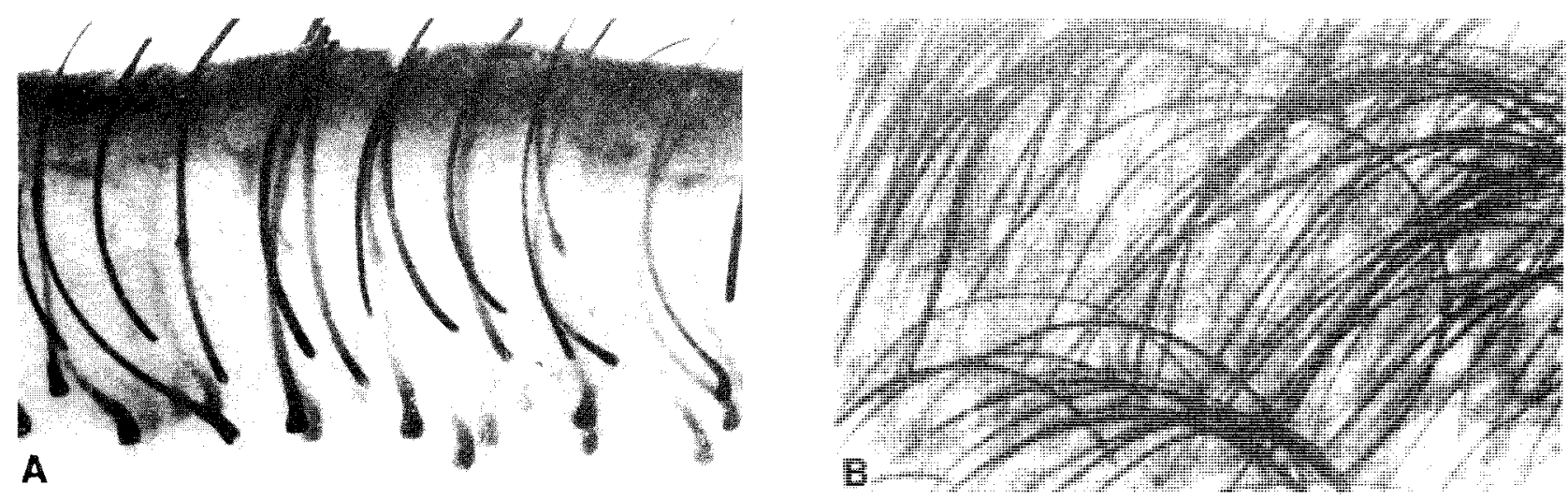

PLATE 6

New Guinea woolly: (A) scalp section; (B) scalp surface.
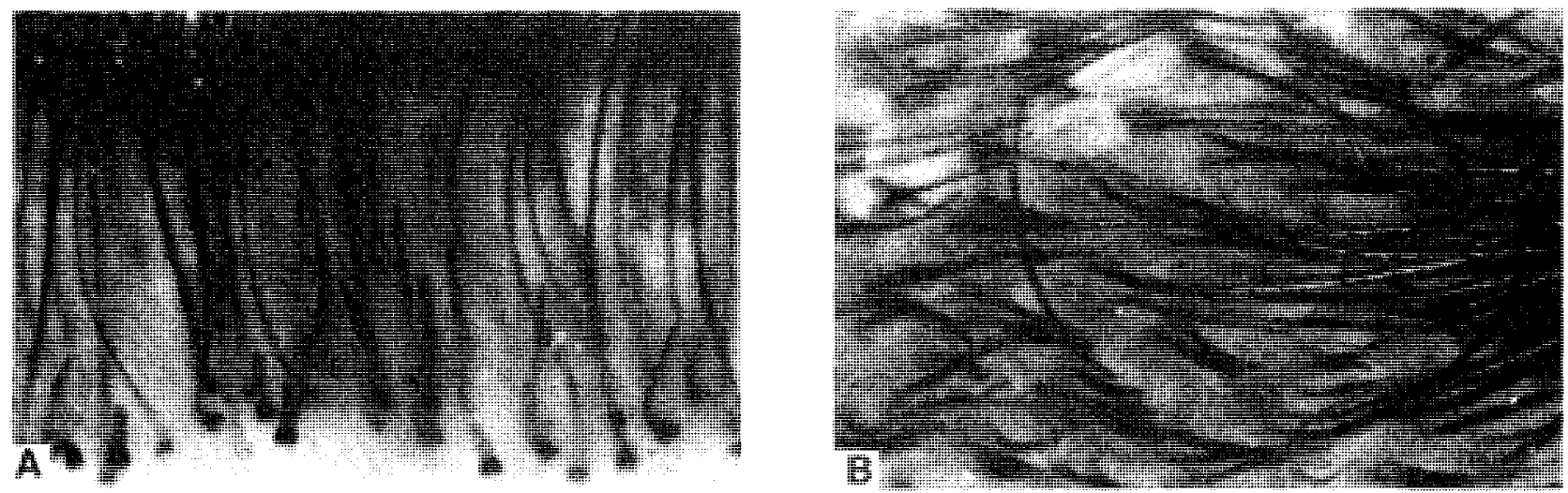

PLATE 7

New Guinea Port Moresby: (A) scalp section; (B) scalp surface.

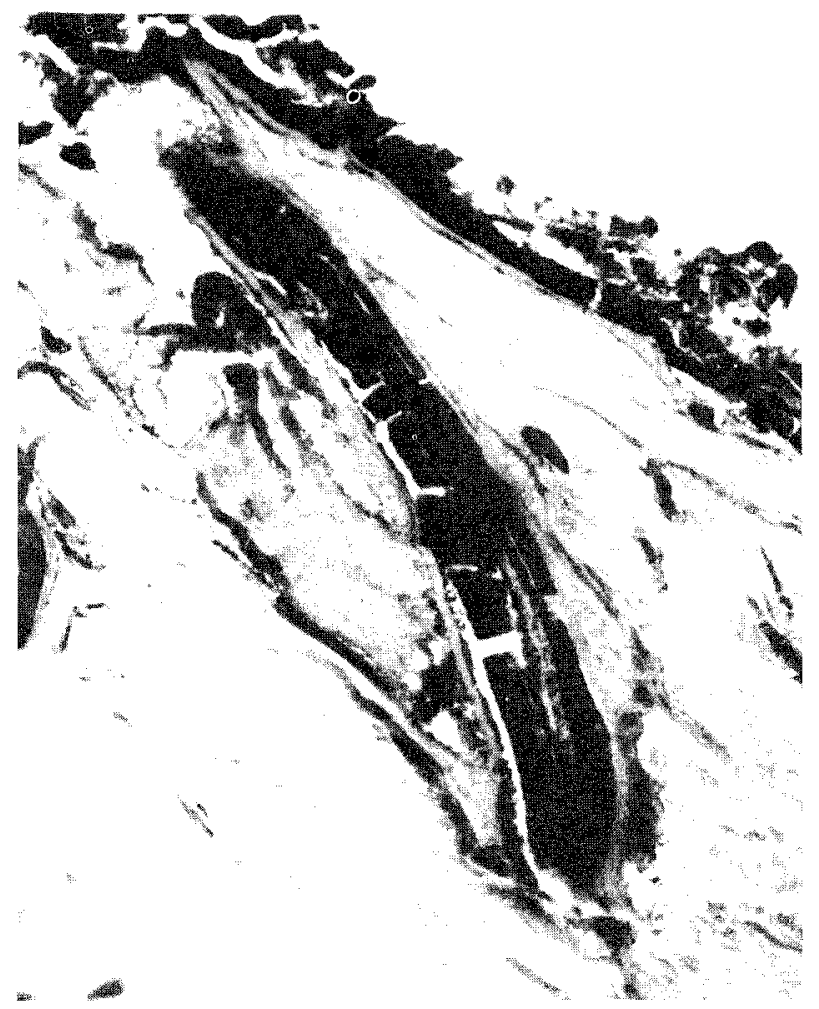

PLATE 8

Tasmanian: scalp section. 


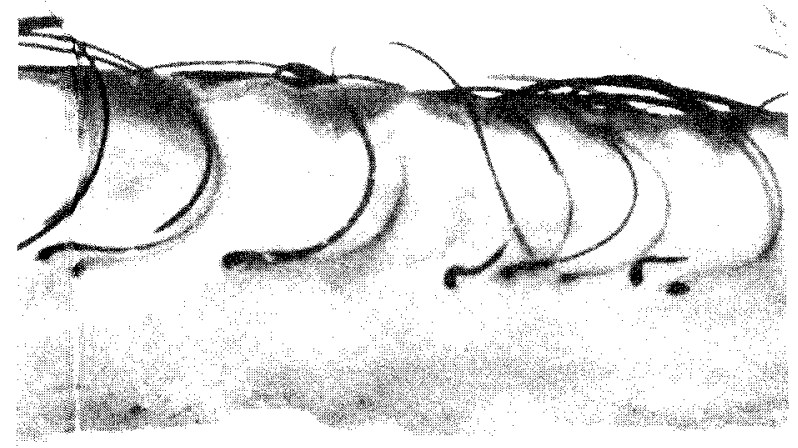

A

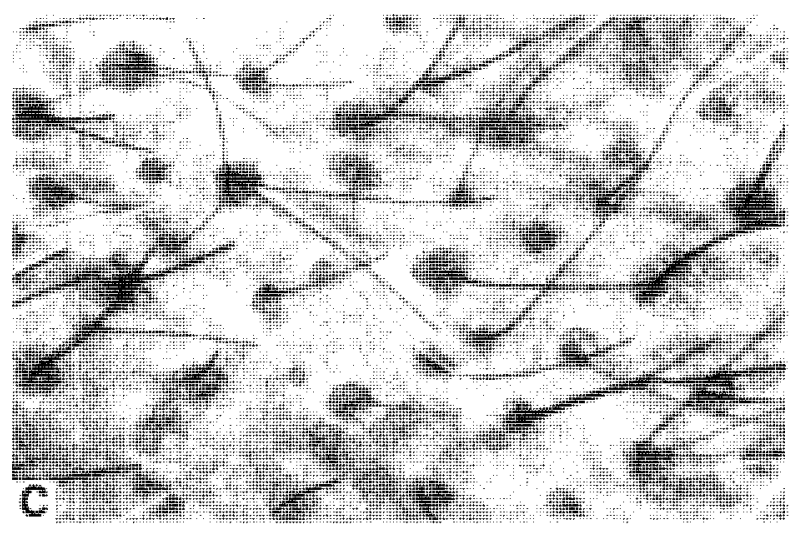

\section{Zulu (PI. 9 A-C)}

Size

A mixture of diameters, but less variation than in Bantu.

\section{Form}

Follicle usually strongly curved, but some less so than others and tending to be straight; the curvatures all in the same direction, so that there is no crossing of the follicles.

\section{Direction}

Follicle meets surface of scalp at right angles; hair continues curvature of follicle.

\section{Density}

Average density less than in Bantu scalp, only one scalp showing the high density found there; follicles show no arrangement at origins, which are all deep; usual to find some arrangement of follicles at surface of scalp, with two, often three, hairs issuing together and on a small pigmented area; the hairs of these doublets and triplets may be of different diameters.

\section{Bulb}

Set at strong angle to shaft.

There are a few reports on the form of the follicle in the writings of others. Bloch \& Vigier (1904) examined the follicles in a Negro of the Congo and found that they were strongly curved, that all lay in the same direction and that two, three and four hairs left the scalp together, so that there were bare areas on its surface. They also found that the hairs

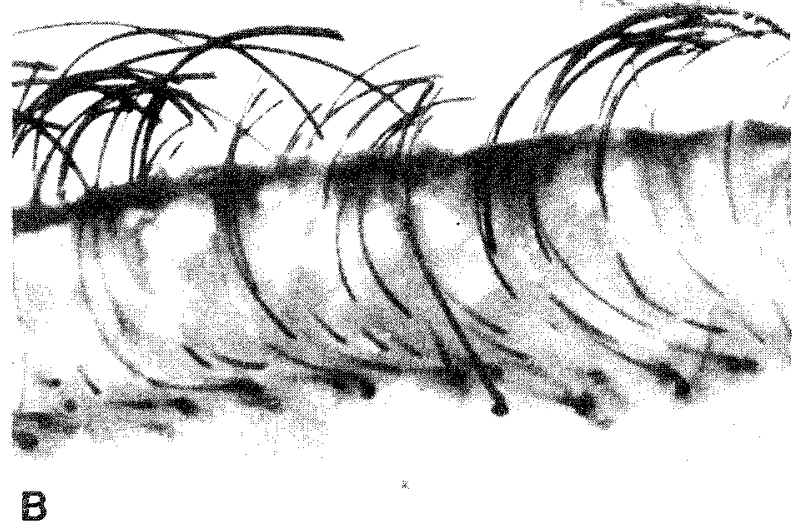

PLATE 9

Zulu: (A) scalp section; (B) scalp section; (C) scalp surface.

were usually elliptical and the individual hairs spiral. Their microscopic section shows that the bulb continued into the shaft of the follicle with a break in direction; and that the curvature of the follicle continued into that of the hair.

Turner (1914) published microscopic sections for the Negro and the Australian aboriginal. In the Negro the shaft was curved, but not markedly so, and the bulb was slightly angled to the shaft. The hairs lay in pairs deeply, one hair always larger than the other. At the surface the hairs emerged in pairs, sometimes three together and occasionally four. In the Australian aboriginal the shaft was straight and directed vertically or nearly so, and the bulb lay at a small angle to the shaft. The follicles reached the surface in groups of three, and the bulbs arose at different depths in the scalp.

\section{DISCUSSION}

Let us first consider the findings concerning hair form in relation to different peoples and the particular types found. Of the various measures of hair form, those of the crosssectional dimensions have been the basis of most studies. Although it is usual to find a mixture of cross-sections among the hairs of the scalp, a particular form predominates in each. There are three main types: the circle, the oval ellipse and the flattened ellipse.

The only comprehensive report on the occurrence of these different forms in a wide range of peoples is that of Pruner-Bey (1865). He dealt with two features of the hair in his classification: one the hair index, that is, the relationship of the larger and smaller diameters of the hair, and the other 
TABLE 2

Occurrence of the three main types of hair form*

\begin{tabular}{|c|c|c|}
\hline & Index & Predominant form ${ }^{\dagger}$ \\
\hline \multicolumn{3}{|l|}{ Circle } \\
\hline Peru & 0.98 & Mostly round, some elongate $(-)$ \\
\hline Japan & 0.96 & Round (2) \\
\hline Peru (mummy) & 0.90 & Nearly circular $(-)$ \\
\hline Mongol & 0.88 & Nearly circular (1) \\
\hline Eskimo & 0.85 & Round to elliptic (2) \\
\hline Siam & 0.82 & Round with some more elongate $(-)$ \\
\hline Choctaw Indian & 0.80 & Nearly circular, ranging to elongate (1) \\
\hline Malay & 0.74 & Circular to oval (1) \\
\hline Lithuania & 0.74 & Oval to circular (2) \\
\hline China & 0.72 & Circular to elliptic $(-)$ \\
\hline Jamba & 0.71 & Circular to oval \\
\hline \multicolumn{3}{|l|}{ Oval ellipse } \\
\hline \multicolumn{3}{|l|}{ Western Pacific: } \\
\hline New Caledonia & 0.80 & Oval elliptic (1) \\
\hline New Zealand & 0.73 & Tendency to circular (3) \\
\hline Australia & 0.72 & Oval elliptic (2) \\
\hline Fiji & 0.71 & Ellipric (4) \\
\hline New Ireland & 0.69 & Oval elliptic (4) \\
\hline Tasmania & 0.65 & Oval elliptic (2) \\
\hline Tikopia & 0.68 & Oval elliptic (2) \\
\hline Nukahiva & 0.61 & Elliptic, tendency to circular (1) \\
\hline \multicolumn{3}{|l|}{ Indian region: } \\
\hline Kole & 0.77 & Most wide oval, tendency to circular (-) \\
\hline Bhil & 0.70 & Oval to elliptic (-) \\
\hline Gond & 0.67 & Mostly elliptic (-) \\
\hline Persia & 0.63 & Oval elliptic (2) \\
\hline Turk & 0.62 & Very elongate (1) \\
\hline Brahman & 0.61 & Oval to elliptic (-) \\
\hline \multicolumn{3}{|l|}{ North Africa: } \\
\hline Algeria & 0.88 & Round to oval (1) \\
\hline Berber & 0.67 & Oval to elliptic (1) \\
\hline Egypt (mummy) & 0.67 & Mostly oval (6) \\
\hline Arab & 0.64 & Elongate elliptic (1) \\
\hline Egypt & 0.54 & Oval (most) to elliptic (2) \\
\hline \multicolumn{3}{|l|}{ Europe: } \\
\hline Basque & 0.76 & Circular-oval-elliptic (3) \\
\hline Italy & 0.75 & Oval (-) \\
\hline Irish (bog) & 0.72 & Oval to elliptic (1) \\
\hline Germany & 0.66 & Oval (4) \\
\hline Irish. & 0.66 & Elliptic-oval-circular (47) \\
\hline \multicolumn{3}{|l|}{ Flattened ellipse } \\
\hline Negro & 0.60 & Elliptic (5) \\
\hline Hottentot & 0.55 & Elliptic (narrow) (1) \\
\hline Papua & 0.42 & Elliptic (2) \\
\hline
\end{tabular}

* From Pruner-Bey 1865.

$\dagger$ The figures in brackets are the numbers of scalps examined, a dash signifying that this is not stated. 
a description of the hair of the scalp in terms of the predominant form present (see table 2 ).

There are some other records of hair index. Sergi (1957) reponed values of 0.73 for Tasmanians and 0.57 for Bu shmen. Neuert (1929, quoted by Sergi 1957) recorded values of 0.98 for Northern Manchuria, 0.79 and 0.82 for Chinese, 0.85 for Peruvians, 0.84 for Tamils, 0.81 for Fuegians and 0.75 for Aztecs. Turner (1914) refers to indices of $0.63,0.67$ and 0.68 for Tasmanians, 0.73 for New Hebrides, 0.70 for New Guinea, 0.51 and 0.53 for the Negro, 0.50 for the Hottentot, 0.52 for the Kaffir, 0.61 for the Andaman, 0.50 for the Semang of Malaya, 0.72 for Australian aborigines, and 0.85 for the Maori of New Zealand.

While sampling error and variability probably account for the differences between the measures for the same people, these differences do suggest that the hair index is not a reliable measure of the characteristic form of the hair in a particular people. Apparently more reliable are Pruner-Bey's descriotions of the predominant form.

Tumer (1914) has drawn attention to another character which contributes to the predominant hair form found in a scalp, the twisting along the length of the hairs. The effect of this twisting differed with the length of shaft between the twists: it was shorter in the woolly hair of the Bushman than in the frizzy hair of the Tasmanians.

Probably relevant to the above is the comment of S.J. Hickson (quoted by Roth 1899) that "the curliness of the hair of the Tasmanians is less than that of any of the Papuans or Andamese, but more than that of the Australians. Thus the average diameter of the curl of the Andamese is $2 \mathrm{~mm}$, of the Papuan $3 \mathrm{~mm}$, of the Tasmanian $5 \mathrm{~mm}$, but in the curliest hair of the Australians the curls are $10 \mathrm{~mm}$ in diameter and the average must be nearly $15 \mathrm{~mm}$.

Another factor in the development of a characteristic hair form is the asymmetry in the deposition of pigment granules along the shaft. Thus, Spearman \& Barnicot (1960) found that in the hair of the Negro of southern Nigeria, a greater density of pigment granules was to be seen on the concave side of the curl. They found the same in the Bantu, Bushman and Hottentot; also some indication of it in wavy European hair, but there was no asymmetry in the distribution of pigment in Chinese hair.

The wide variety of characters to be found in scalp hair of a particular form, a number of which have been mentioned in the above review, points to the futility of seeking a basic set upon which either to classify a predominant hair form or to explore human relationships in reference to it. It seems better to acknowledge that, because the hair is the end product of follicular activity, then any system of classification or means of comparing different peoples should be based on follicular characters.

During the development of the different isolates of humans, the genes concerned with the production of the hair have pursued different courses in the formation of isolates. One has only to point to the occurrence of a mutation in a Northern European family which has produced spiral hair (Schlaginhaufen 1945); not to mention the spiral form in the aborigines of Tasmania, who have been derived from an isolate of the people who occupied southeastern Australia about 10000 years ago.

We have here a means of comparing populations by appropriate methods of statistical analysis. The characters of the follicle provide bases for study by such methods. To describe the follicle in a limited number of ways, as in this study, enables comparisons to be made.

It might be mentioned, by the way, that the present study provides a means of identifying a bare scalp in forensic examinations.

Two things have been demonstrated in our work, one that a particular human isolate can be characterised by the form of the hair follicle, and the other that similar hair forms can arise in different types of follicle.

\section{ACKNOWLEDGEMENTS}

We are very much indebted to the many people on the staffs of hospitals and universities in several countries who, between 1961 and 1965, provided the material upon which this study has been based.

\section{REFERENCES}

Bloch, A. \& VigIER, P., 1904. Recherches histologiques sur le follicule pileaux et le cheveu de deux Nègres décédés a Paris. Bull. Mem. Soc. anthrop. Paris 5(2): 124-132.

Plomiey, N.J.B. \& Baldowin, F., 1964. The hair follicle in the Tasmanian aborigines. Exhibit at meeting of Anatomical Society of Great Britain, Sydney, NSW, 5-6 February 1964.

PRUNER-Bey, 1864. On human hair as a race-characrer, examined by the aid of the microscope. Anthrop. Rev. 2: 1-23.

Pruner-Bey, 1865. De la chevelure comme charactéristique des races humaines. Mem. Soc. Anthrop. Paris 2: 1-35, pls 1-3.

RoTH, H. LING, 1899. THE ABORIGINES OF TASMANLA. Halifax.

SchlaginHaufen, O., 1945. Helicotrichie in einem schweizerischen Stammbaum. Arch. Julius Klaus-Stiftung 20: 201-216, pls $1-10$.

Sergi, S., 1957. Capelli di Tasmaniano e di Boscimanos. Riv. Antrop. Roma 44: 285-316, pls 1-10.

SPEARMAN, R.I. \& BARNicot, N.A., 1960. A study of the bilaterality of human hair. Am. J. phys. Anthrop. 18: 91-94, pl.1.

Trotter, M., 1938. A review of the classification of hair. Am. J. phys. Anthrop. 24: 105-126.

TURNER, W., 1914. The aborigines of Tasmania. Part III. The hair of the head comparied with rhat of other Ulotrichi and with Australians and Polynesians. Trans. R. Soc. Edin. 50:309347.

(accepted 9 August 1991) 